\title{
MULTIPLICAR ESCOLAS E ESTAR NA CULTURA: ALGUMAS CONSIDERAÇÕES SOBRE A ESCOLA DOS TUPINAMBÁ DE OLIVENÇA/BA
}

\author{
José Valdir Jesus de Santana (UESB)* \\ https://orcid.org/0000-0001-7215-2562 \\ Clarice Cohn (UFSCar)** \\ https://orcid.org/0000-0002-5446-7891
}

\section{RESUMO}

Neste artigo pretendemos demonstrar, a partir da etnografia realizada sobre a escola dos Tupinambá de Olivença (BA), como esta instituição tem se tornado central para a defesa e demarcação do território, sobretudo nas áreas de retomadas. Ademais, interessa-nos refletir sobre a centralidade da escola para a produção de pessoas fortes na cultura, atualização e produção de parentesco e para aquilo que os Tupinambá definem como no estar na cultura. Nesse sentido, estar na cultura, para os Tupinambá, se traduz no processo de construir coletividades, e a escola tem sido um vetor importante nesse processo.

Palavras-chave: Cultura. Escola. Retomada. Tupinambá.

\section{ABSTRACT}

\section{MULTIPLYING SCHOOLS AND BEING IN CULTURE: SOME CONSIDERATIONS ABOUT THE TUPINAMBÁ'S SCHOOL FROM OLIVENÇA/BA}

In this article we intend to demonstrate, from the ethnography performed about the Tupinambá's school from Olivença (BA), how this institution has become central to the territory defense and demarcation, especially in the areas of retaking. In addition, we are interested to reflect about the school centrality for the strong people production in culture, updating and production of kinship and what the Tupinambá define as being in culture. In this sense,for the Tupinambás,

\footnotetext{
Doutor em Antropologia Social pela Universidade Federal de São Carlos (UFSCar). Professor adjunto do Programa de PósGraduação em Relações Étnicas e Contemporaneidade e do Programa de Pós-Graduação em Ensino da Universidade Estadual do Sudoeste da Bahia (UESB). Coordena o Grupo de Pesquisa Educação para as Relações Étnico-raciais: o que nos dizem as crianças? e o Grupo de Pesquisa em Educação Escolar Indígena no Estado da Bahia: experiências entre os Povos indígenas Tupinambá, Pataxó e Pataxó Hã Hã Hãe. E-mail: santanavaldao@yahoo.com.br

** Pós-Doutorado pela Université Paris Ouest Nanterre La Défense. Doutora em Antropologia Social pela Universidade de São Paulo (USP). Professora adjunta do Departamento de Ciências Sociais e do Programa de Pós-Graduação em Antropologia Social da Universidade Federal de São Carlos (UFSCar). Coordena o Laboratório de Estudos e Pesquisas em Antropologia da Criança da Universidade Federal de São Carlos (LEPAC/UFSCar). E-mail: clacohn@gmail.com
} 
being in culture, translates into the process of building collectivities and the school has been an important vector in this process.

Keywords: Culture. School. Resumed. Tupinambá.

\section{RESUMEN}

\section{MULTIPLICAR ESCUELAS Y ESTAR EN LA CULTURA: ALGUNAS CONSIDERACIONES A CERCA DE LA ESCUELA DE LOS TUPINAMBÁ DE OLIVENÇA/BA}

En este artículo pretendemos demostrar, a empezar de la etnografía realizada a cerca de la escuela de los Tupinambá de Olivença (BA), como esta institución tiene se convertido central para la defensa y demarcación del territorio, sobre todo en las áreas de reanudadas. Además, nos interesa reflejar acerca de la centralidad de la escuela para la producción de personas fuertes en la cultura, actualización y producción de parentesco y a aquello que los Tupinambá definen como en lo estar en la cultura. En ese sentido, estar en la cultura, para los Tupinambá, se traduce en el proceso de construir colectividades y la escuela tiene sido un vector importante en ese proceso.

Palabras-clave: Cultura. Escuela. Reanudada. Tupinambá.

\section{Introdução}

Em nossa tese de doutorado, buscamos compreender como e por que os Tupinambá de Olivença (BA) fazem escola e como esta tem se tornado central para a defesa e demarcação do território, posto que é através das ações de retomadas ${ }^{1}$ que a escola de expande pelo território. Ademais, a escola tem sido central para a produção de pessoas fortes na cultura, atualização e produção de parentesco e para aquilo que os Tupinambá definem como no estar na cultura, tão bem discutido por Mejía Lara (2012).

Para os Tupinambá, tornar-se "forte na cultura" implica em compartilhar memórias, afetos, em estar juntos (VIEGAS, 2003, 2007), em produzir cultura e, para que isso ocorra, a escola tem se tornado central; do mesmo modo,

1 "Retomadas" consistem em processos de recuperação, pelos indígenas, de áreas por eles tradicionalmente ocupadas, no interior das fronteiras da Terra Indígena (TI), e que se encontravam em posse de não índios. São ações encabeçadas por um cacique, algumas de suas lideranças e famílias indígenas que, ao identificarem uma área improdutiva ou abandonada dentro da TI, investem na ocupação territorial da mesma (ALARCON, 2013; MEJÍA LARA, 2012; ROCHA, 2014). como dizem os Tupinambá, a escola tem sido, ademais, o lugar da cultura, processo que tem sido observado em outros contextos, como nos demonstram Weber (2006) em sua etnografia sobre os Huni Kuin e Mainardi (2010a, 2010b) sobre os Tupi Guarani. 0 texto aqui apresentado é, portanto, resultado da referida tese e de pesquisa que temos desenvolvido junto aos Tupinambá.

Compreender como cada povo indígena tem produzido suas escolas é de fundamental importância, posto que, como já nos advertiu Sahlins (2004, p. 184), "nenhum objeto, nenhuma coisa existe ou tem movimento numa sociedade humana exceto pela significância que os homens lhe possam atribuir". Nesse sentido, são muitos os sentidos e significados que os povos indígenas, a exemplo dos Tupinambá, têm atribuído à escola, através de suas "políticas culturais", como propõe Carneiro da Cunha (2014). A etnografia (COLLET, 2006; LOPES DA SILVA, 2001; PEIRANO, 1995), portanto, se torna fundamental para a compreensão desses processos. A pesquisa realizada junto aos Tupi- 
nambá, que resultou na tese de doutorado de Santana (2015), teve início em abril de 2011 e se estendeu a maio de 2012. Retornamos a campo entre fevereiro e março de 2013 e em setembro de 2014. No entanto, continuamos, até o presente momento, desenvolvendo pesquisa junto a esse povo.

Neste artigo, o nosso objetivo e recuperar a história de construção de alguns Núcleos que formam o Colégio Estadual Indígena Tupinambá de Olivença, especialmente aqueles que estão em áreas de retomadas, de forma a demonstrar a centralidade que a escola ocupa entre os Tupinambá. Para a compreensão da configuração mais atual da Escola (ou escolas) dos Tupinambá de Olivença, ver as dissertações de Magalhães (2019) e Santos (2016), ambos indígenas pertencentes a esse povo.

\section{A escola sede e os núcleos: escolas e retomadas}

De acordo com dados da Secretaria Especial de Saúde Indígena (SESAI/Bahia), em 2011, os Tupinambá contabilizavam 4.486 indivíduos, configurando a segunda maior etnia no Estado. Os Tupinambá estão distribuídos em diferentes comunidades que estão dispostas em uma extensão aproximada de 47 mil hectares e que compreendem os municípios de Ilhéus, Buerarema e Una. Estes limites geográficos já foram reconhecidos como Terra Indígena e abarcam ambientalmente paisagens muito distintas que se estendem desde a costa litorânea até a região serrana de mata atlântica (ROCHA, 2014).

Olivença, área próxima ao litoral, fora no passado um antigo aldeamento jesuíta, denominado de Nossa Senhora da Escada, que preserva até hoje a arquitetura quadricular e a igreja construída em meados de 1700. A maioria das famílias de nativos foi expulsa da vila durante a primeira metade do século XX, mas algumas conseguiram permanecer e outras acabaram voltando posteriormente, sendo que hoje se constata a presença tanto de moradores indígenas quanto de não indígenas (MARCIS, 2004; ROCHA, 2014; VIEGAS, 2007).

0 movimento indígena de organização dos atuais Tupinambá se configura desde os anos 1980, mas ganha corpo principalmente a partir do final dos anos de 1990, quando uma mulher nativa, Núbia Batista da Silva, com formação escolar superior (graduação em Pedagogia pela Universidade Estadual de Santa Cruz, Ilhéus, Bahia) e ligada a uma organização não governamental de alfabetização, o Coletivo de Alfabetizadores Populares da Região Cacaueira (CAPOREC), passa a mobilizar as famílias de diversas localidades, que hoje compõem o perímetro da Terra Indígena Tupinambá de Olivença. É nesse contexto de mobilização e reorganização interna que a educação escolar indígena começa a ser pensada e construída de modo a atender às necessidades deste povo, buscando atuar em duas frentes: a luta pelo reconhecimento étnico e a retomada de seu território ancestral. 0 que se vislumbra, a partir desse novo contexto, é uma escola que seja produzida pelos e para os Tupinambá.

O projeto de educação escolar iniciado a partir de 1996, sob a liderança de Núbia Batista da Silva, ganha força à medida em que um grupo de professores começa a trabalhar voluntariamente para alfabetizar os moradores da aldeia. Estimulados por Núbia, essas professoras participaram do CAPOREC, responsável pelo acompanhamento e assessoria pedagógica, cuja proposta estava fundamentada na obra de Paulo Freire e consistia nos seguintes passos: primeiro, a identificação e motivação das famílias da comunidade; segundo, o levantamento das expectativas dos alfabetizadores; terceiro, o trabalho partindo das histórias de vida (SILVA, 2006). Assim, ao estudar e problematizar a realidade, as questões étnicas vieram à tona nas histórias de vida dos alfabetizadores e das alfabetizadoras que foram se somando ao movimento. Ao se assumirem indígenas, muitos alfabetizadores integram-se às atividades de formação e articulação política que preparavam as atividades paralelas à Comemoração 
dos 500 anos do Descobrimento do Brasil. Essa participação proporcionou ao grupo maior experiência e conexão com os demais povos indígenas, evidenciando a necessidade da definição étnica, já bem retratado por Viegas (2007), Ferreira (2011, 2013), Magalhães (2010) e Alarcon (2013). Nesse sentido,

Esse movimento, protagonizado por Núbia e alguns outros professores, contribuiu sobremaneira na organização da comunidade para o reconhecimento étnico pela Fundação Nacional do Índio (FUNAI), em 2002, e a identificação do território Tupinambá de Olivença, atualmente em processo, com a publicação do relatório preliminar de demarcação das terras pela FUNAI, em 20 de abril de 2009, com área proposta de 47.376 ha, abrangendo os municípios de Ilhéus, Buerarema e Una. (MESSEDER; FERREIRA, 2010, p. 189).

O movimento que multiplica a escola pelo território indígena, em especial pelas áreas de retomadas, através dos processos de nucleamento, tem sido central para a compreensão da importância que a escola assume entre os Tupinambá que, como já demonstrado em nossa tese de doutorado, está articulado à luta pela demarcação e defesa do território, à defesa do parentesco, à produção da cultura e ao estar na cultura, além da construção da identidade (COHN; SANTANA, 2016; MEJÍA LARA, 2012; SANTANA, 2015). Ademais, como demonstrado por Rocha (2014), a produção da escola e sua dispersão pelo território também se articula e é articulada pela forma como os Tupinambá fazem política.

Recuperaremos a história de alguns Núcleos, muitos deles localizados em áreas de retomada, sobretudo dos que mantivemos maior contato durante a pesquisa que deu origem à nossa tese. Cabe ressaltar, ainda, que o movimento que expande a escola pelo território não é uniforme e, nesse sentido, varia no tempo e está relacionado a distintos fatores, como conflitos que atravessam a luta pela demarcação do território, aos processos de reintegração de posse perpetrados pelo Estado (forma autoritária, truculenta, no atendimento aos interesses dos latifundiários); outro fator diz respeito ao modo como o Estado funciona, no que concerne ao mínimo de alunos necessários para fazer um Núcleo funcionar (alguns Núcleos são desativados diante da escassez de alunos, especialmente quando os conflitos territoriais se acirram, fazendo com que famílias tenham que se deslocar para outras áreas).

Apresentaremos, a seguir, a distribuição da escola pelo território, posto que tem sido através dos processos de nucleamento que a escola tem se multiplicado por toda a Terra Indígena. Esta distribuição nos permitirá ver como se organizam, hoje, as escolas, mas também o movimento atual pelo território, pelas retomadas, e como as escolas estão ligadas a ele, uma vez que este movimento aciona a produção e atualização do parentesco, de pessoas fortes na cultura e o estar na cultura, como já referido.

Á época de nossa pesquisa, a Escola Estadual Indígena Tupinambá de Olivença era constituída por Núcleos que se distribuíam pelas comunidades que compõem a Terra Indígena, sendo, portanto, extensões da escola em Sapucaeira. Muitos desses Núcleos funcionavam com salas multisseriadas que atendiam a crianças e jovens de educação infantil e dos primeiros anos do ensino fundamental. Em 2014, existiam 17 Núcleos, localizados nas comunidades de Olivença, Águas de Olivença, Taba Jairy, Acuípe do Meio I, Acuípe do Meio II, Acuípe de Cima, Mamão, Tamandaré, Santana, Santaninha, Abaeté, Maruim, Serra das Trempes, Serra Negra, Tucum, Itapoã e Gravatá. Neste mesmo ano, mais da metade dos estudantes da Escola Estadual Indígena Tupinambá de Olivença, ${ }^{2}$ aproximadamente 590, estavam distribuídos por estes Núcleos. Entre Núcleos e escola sede, havia um total de 94 professores, sendo 18 concursados, 51 Prestadores de Serviço Temporário (PST) e 25 em Regime Especial de Direito Administrativo (REDA).

O Núcleo de Acuípe de Baixo, em julho de 2014, é tornado colégio, desligando-se, por-

2 Em julho de 2014, torna-se Colégio Estadual Indígena Tupinambá de Olivença, através da Portaria no 5.745/2014. 
tanto, da escola sede e passando a se chamar Colégio Estadual Indígena Tupinambá de Acuípe de Baixo.

\section{A escola sede: Sapucaeira}

A sede do Colégio Estadual Indígena Tupinambá de Olivença atendia a todos os níveis de ensino (educação infantil e ensinos fundamental e médio), além da modalidade de Educação de Jovens e Adultos (EJA), nos turnos matutino, vespertino e noturno. A EJA funcionava somente no noturno. No turno matutino funcionavam o ensino fundamental do $6^{\circ}$ ao $9^{\circ}$ ano e o ensino Médio (do primeiro ao terceiro ano). Quando iniciei a pesquisa, a primeira turma de ensino médio tinha iniciado em 2010 (somente uma turma do primeiro ano); em 2011, existiam duas turmas (uma de primeiro e outra de segundo ano). A Educação Infantil (pré-escola) e o ensino fundamental do primeiro ao quinto ano funcionavam, quase em sua totalidade, no turno vespertino. No matutino funcionava uma única turma multisseriada (do primeiro ao quinto ano) para atender as necessidades e demandas de algumas famílias, posto que seus filhos mais velhos estudavam no matutino (cursando os últimos anos do ensino fundamental ou o ensino médio). A justificativa dos pais, que pude presenciar em muitas situações, era apresentada nos seguintes termos: aos filhos mais velhos caberia o cuidado das crianças menores que se deslocavam nas toyotas, consideradas perigosas por esses pais, que não se sentiam seguros em mandar seus filhos para a escola no turno vespertino. Esta demanda trazida pelos pais fez com que a direção da escola formasse essa turma multisseriada.

A escola sede, no formato arquitetônico atual, foi inaugurada em 2006, atendendo incialmente a alunos da educação infantil e do ensino fundamental. Foi construída na Fazenda São Pedro, Km 16, na Região de Sapucaieira, em uma área doada por uma família de indígenas. Nesta mesma localidade, e a partir da contribuição e articulação desta família, tem início o movimento de organização dos Tupinambá de Olivença em torno de uma educação escolar que servisse aos interesses desse povo, cujo processo está melhor detalhado na tese de Santana (2015). É com esta família, em um espaço improvisado, que começa a atuar uma das primeiras professoras Tupinambá, Pedrísia Damásio, no Núcleo de Sapucaieira; este Núcleo foi pioneiro no processo de escolarização com práticas pedagógica diferenciadas, mesmo antes da construção do atual Colégio.

A escola possui $5.000 \mathrm{~m}^{2}$, construída em formato circular, com padrões arquitetônicos inspirados em uma aldeia Tupinambá do século XVII, sendo uma das primeiras escolas no estado da Bahia a ser construída num modelo arquitetônico escolhido pela comunidade. Não possui muros externos e oferece uma infraestrutura de oito salas de aula, sala de vídeo, cozinha, anfiteatro, laboratório de informática, salas de administração, biblioteca, museu, quadra poliesportiva, um consultório odontológico e três sanitários (COSTA, 2013).

Em Sapucaeira, na ausência de professores, fui acionado para aplicar atividades ou observar os estudantes em dias de avaliação (testes e provas); em outras situações, diante da ausência de professor, tive que ministrar aulas (em duas situações, ministrei aulas de história para turmas do sexto e do oitavo ano; em outra, ministrei aulas de Língua Portuguesa para turmas de Educação de Jovens e Adultos, ${ }^{3}$ no noturno) como forma de socorrer a escola, como diziam Cleusa e Gicélia, diretora e vicediretora, respectivamente, da Escola Estadual Indígena Tupinambá de Olivença à época.

Alguns dos professores "faltosos" (em sua maior parte) estavam na Universidade Estadual de Santa Cruz (UESC), nos cursos de licencia-

3 Os estudantes do noturno eram os que mais reclamavam da ausência de professor, posto que, segundo estes, "saíam de suas casas, depois de um dia de trabalho e com muito cansaço, para irem ter aula em Sapucaeira e não encontrar professor". Os estudantes da turma de EJA vinham de diferentes comunidades, muitas delas distantes, com estradas muito precárias. Faziam, de fato, grande esforço para estudar. É certo, porém, que a evasão, nessas turmas, ao longo do ano, era muito alta. No final do ano, algumas turmas terminavam com pouquíssimos estudantes. 
turas em Ciências Sociais, Matemática, História e Educação Física, através do Programa Nacional de Formação de Professores da Educação Básica (PARFOR), do Governo Federal; outros faziam a Licenciatura Intercultural Indígena, oferecida pela Universidade do Estado da Bahia (UNEB), ${ }^{4}$ cujas aulas aconteciam em formato modular, no Campus de Teixeira de Freitas, Extremo-Sul da Bahia, ou em Paulo Afonso, Norte da Bahia. Outros professores faziam a Licenciatura Intercultural Indígena oferecida pelo Instituto Federal da Bahia (IFBA), em Porto Seguro. Alguns faziam, ao mesmo tempo, duas graduações, a Intercultural Indígena e outra na UESC ou em Universidades particulares.

Os cursos oferecidos pela UESC (Ilhéus) e as Licenciaturas Interculturais (Teixeira de Freitas, Paulo Afonso e Porto Seguro), mesmo ocorrendo de forma modular, afastavam os professores da sala de aula por semanas, sobretudo os que faziam as Licenciaturas Interculturais. As ausências dos professores na escola, no período das aulas, causavam apreensões e preocupações aos gestores da escola, aos estudantes e aos pais. Alguns professores resolviam suas ausências firmando acordos com os colegas que permaneciam na escola, de modo que estes assumiam suas aulas. Outros deixavam atividades elaboradas para serem aplicadas às turmas (tanto por um colega professor como por alguém da direção, geralmente Gicélia, Erlon e Gilmara, esta última, secretária na escola). Outros, ainda, deixavam a cargo da direção organizar o funcionamento das aulas em suas ausências. Segundo os gestores, tais ausências, além de causarem transtornos ao funcionamento da escola, comprometiam a qualidade da educação (contudo, os gestores sempre mantiveram esforços a fim de garantir a saída dos professores e o funcionamento da escola). Não obstante as tentativas para que a escola funcionasse nessas circunstâncias, nem sempre era possível, sendo comum os estu-

4 Sobre a construção da Licenciatura Intercultural Indígena, no âmbito da Universidade do Estado da Bahia, ver Messeder (2013). dantes chegarem à escola e encontrarem aulas vagas. Situações como essas faziam com que as aulas terminassem mais cedo e não foi raro encontrar estudantes insatisfeitos, recorrendo à direção para que esta tomasse providências. Nos Encontros Pedagógicos e nas reuniões com os professores, essas queixas eram recorrentes.

Por outro lado, os professores que se responsabilizavam pelas aulas dos colegas ausentes nem sempre conseguiam dar conta; em alguns casos, revezavam entre duas ou três turmas diferentes ao mesmo tempo, o que causava grande cansaço e aborrecimento tanto ao professor quanto à direção, posto que era comum encontrar alunos circulando livremente pela escola. Alguns alunos, em tom de ironia, afirmavam que "a melhor aula era a aula vaga" e aproveitavam o momento para "colocar a conversa em dia" com os colegas, ouvir música no celular (geralmente de forma alta, o que causava desespero à direção), jogar futebol na quadra poliesportiva ou no anfiteatro da escola.

Esta "desordem" acontecia, quase sempre, no turno matutino, onde funcionavam o ensino fundamental do $6^{\circ}$ ao 9 음 ano e ensino médio, e no noturno, com as turmas de Educação de Jovens e Adultos, justamente nos dois níveis de ensino onde se concentravam a maior parte dos professores que estavam nas referidas licenciaturas. 0 vespertino, no qual funcionava a educação infantil e os primeiros anos do ensino fundamental, sempre foi considerado "mais organizado e com menores problemas", posto que era mais fácil organizar a rotina da escola na ausência de algum professor, uma vez que nas salas de educação infantil era comum encontrar dois professores, o titular e um auxiliar, que, nestas situações, era deslocado para assumir a sala do(a) professor(a) ausente.

No caso do ensino fundamental II e ensino médio, as disciplinas que "ficavam mais prejudicadas" com a ausência do professor eram as de ciências exatas, posto que era mais difícil encontrar professor substituto ou até mesmo alguém que pudesse aplicar alguma atividade para os estudantes, quando este deixava. Em 
muitas dessas situações, a direção da escola construía saídas, seja pedindo aos estudantes que elaborassem redação, já que para os gestores era na escrita que estava uma das maiores dificuldades que a escola enfrentava (e que, segundo estes, refletia-se na qualidade da educação), ou aproveitando a ocasião para fazer reuniões com os estudantes.

Contudo, como discutimos ao longo da tese de Santana (2015), os Tupinambá não querem uma escola que se limite, apenas, a ensinar a ler e escrever e, dessa forma, o que é considerado uma "boa escola", em nossos termos, é uma dimensão valorizada, mas não a única, isso porque a "escolaridade não está só no ler e escrever, está na nossa identidade, está no conhecimento dos nossos valores, está na nossa cultura", como ouvi certa vez de uma professora. Por isso que a escola é valorizada, e "não ter aula", "não ter escola" é sempre um problema, sobretudo para os estudantes e suas famílias. As queixas que estes apresentavam iam sempre nessa direção e, por vezes, muitos estudantes abandonavam a escola ou pediam transferência. Não faziam isso porque consideravam a escola ruim ou de qualidade duvidosa (ao menos não eram esses os argumentos recorrentes), mas reclamavam da ausência dos professores, da interrupção das aulas devido a problemas no transporte escolar ou quando estas eram interrompidas durante os períodos mais chuvosos, que inviabilizavam o funcionamento da escola, já que o transporte não conseguia circular pelas comunidades. Não ter escola, e aqui nos referimos a não ter aula, é um problema para os Tupinambá, inclusive muitos pais veem nisso motivo para tirar seus filhos desta.

O que queremos reiterar é que o que constitui "ameaça" à escola ou o que é motivo de preocupação para os Tupinambá não é a suposta "falta de qualidade" do ensino oferecido (é claro que é uma questão que mobiliza os Tupinambá, mas não pareceu, ao menos durante nossa pesquisa, a mais importante, nem por parte da grande maioria dos professores nem dos estudantes ${ }^{5}$ ), como muitos imaginam - inclusive os representantes da Secretaria de Educação, da Diretoria Regional de Ensino (Direc 6), localizada em Ilhéus, que não perdiam a oportunidade em lembrar que o "Índice de Desenvolvimento da Educação Básica - IDEB ${ }^{6}$ da escola indígena é muito baixo" -, mas sim o não funcionamento desta; isso porque, como apresentamos, é na escola e através dela que os Tupinambá atualizam relações, parentesco, aprendizados, produzem cultura, tornam-se fortes, constroem sentimento de pertença e de luta pelo território.

\section{Núcleo Acuípe do Meio I}

Neste Núcleo, a educação tem início em 2001, a partir dos esforços construídos pelas professoras Lucimeire e Josenice. ${ }^{7}$ Neste mesmo ano, estas professoras começaram a lecionar em uma casa de farinha cedida pelo senhor Dernival. Todavia, no ano seguinte, diante da impossibilidade em se ter aula regularmente, durante todo o período letivo, em virtude do tempo dedicado à produção da farinha neste local, as professoras se deslocaram para um bar e depois para um galinheiro. A professora Luziane se junta às demais professores $\mathrm{e}$ passa a ministrar aulas, diante da procura e do aumento no número de estudantes que recorrem à escola. Ainda em 2002, a professora Josenice organiza uma turma própria em um galpão construído pela organização não

50 que não significa dizer que alguns professores e estudantes não estejam empenhados na discussão acerca da necessidade de uma "educação de qualidade". Em campo, as discussões em torno da "qualidade da educação" se faziam presentes em conversas que tive com José Carlos, Diane e Ana Cláudia. Todavia, em conversas que tivemos com famílias da comunidade de Tucum (especialmente as mulheres, mães de estudantes), a preocupação em torno da qualidade da educação oferecida pela escola indígena é mais generalizada.

6 Em 2011, o IDEB da Escola Estadual Indígena Tupinambá de Olivença era de 1,3 .

7 É uma importante liderança desta comunidade; além de atuar como professora, atua como Agente de Saúde pelo Município de Ilhéus, concursada nesta última função. Ouvi de muitos Tupinambá que Josenice tinha as qualidades para se tornar cacique desta comunidade. 
governamental CARE (este galpão tinha sido construído para beneficiamento de piaçava dos moradores desta comunidade. Era utilizado, ademais, para reuniões, atendimento médico, vacinação, reuniões evangélicas e como depósito de mercadorias dos moradores). Neste galpão, em uma parte, funcionavam as turmas de $1^{\underline{a}}$ e $2^{\text {a }}$ séries (atuais segundo e terceiro anos). No galinheiro funcionavam as turmas de educação infantil (pré-escolar).

Em 2009, a parte do galpão que servia como depósito é desocupada e passa a abrigar a educação infantil. No matutino funcionava a turma de $2^{\mathrm{a}}$ série e a de educação infantil. No

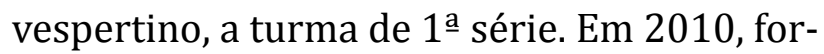
ma-se uma turma de $3^{\text {a }}$ série (quarto ano). No ano seguinte, uma turma de $4^{\underline{a}}$ série (quinto ano). Em 2013 e 2014 funcionavam neste Núcleo turmas de educação infantil e do $1^{0}$ ao $5^{0}$ ano, atendendo a cerca de 50 estudantes, tendo como professoras Lucimeire, Élen França, Sebastiana, Rosimeire e Geane. Josenice encontrava-se afastada da sala de aula por estar com problemas nas cordas vocais, mas continuava atuando na escola em funções de "coordenação pedagógica”, na organização das reuniões com as famílias dos estudantes, juntamente com a direção da escola, tanto nos Núcleos quanto na escola sede.

Por muitas vezes ouvi da direção da escola que este Núcleo era um dos "mais organizados, com educação de qualidade", fruto da responsabilidade das professoras que ali lecionavam. Segundo Cleusa, Josenice atuava como um tipo de "diretora" e, como consequência, "professor(a) que não levasse a sério o trabalho nesta comunidade não permanecia por muito tempo lecionando".

Os estudantes que chegavam à escola sede, vindos deste Núcleo, eram considerados "adiantados", o que, segundo os gestores, comprovava a qualidade da educação e o comprometimento das professoras. De fato, em muitas conversas que tive com Josenice e sua irmã Élen França, nos encontros para elaboração do Projeto Político Pedagógico da Escola e nas reuniões que ocorreram no Núcleo, elas sempre enfatizavam a necessidade de uma educação de qualidade e que estivesse para valorizar a cultura. Em uma destas ocasiões, em abril de 2011, Élen relata:

Por meio da educação foi se resgatando o uso da cultura e as demais coisas mencionadas pelo conhecimento e incentivo que os alunos recebiam na escola. Assim, os índios iam se reconhecendo cada vez mais e se valorizando. A cultura e arte na educação caracteriza a escola, valoriza, reconhece, destaca e divulga a educação indígena, pois ajuda a desenvolver a cultura, a arte, música, rituais e conhecimento já existente na aldeia.

Em 2014, neste Núcleo estavam matriculados 45 estudantes, distribuídos entre os turnos matutino e vespertino, na educação infantil e nos primeiros anos do ensino fundamental, em turmas multisseriadas (do primeiro ao sexto ano). Lecionavam no referido Núcleo: Élen França Amorim e Jaqueline Souza Reis (educação infantil); Sebastiana Souza Vieira do Amaral e Rosemeire dos Santos (educação infantil e quinto ao sexto anos); Lucimeire Magalhães dos Santos (primeiro e segundo ano); Lindiane Valentim Santos (terceiro e quarto ano).

\section{Núcleo Acuípe do Meio II}

Na área entre o Acuípe do Meio I e o Acuípe de Cima vivem famílias aparentadas entre si e com estas comunidades mais próximas. A maioria das famílias vive em terrenos recebidos de herança e se conhecem há bastante tempo (ROCHA, 2014).

Segundo a professora Maristela Santos, "a educação na comunidade começou depois que surgiu o movimento indígena", tendo início em 2000, quanto esta, juntamente com o professor Roquelino, começaram a lecionar na comunidade, recebendo apoio pedagógico de Núbia Tupinambá. Inicialmente, é improvisada uma sala de aula na casa de seu pai. Em 2001, por já ter formado uma turma com aproximadamente 52 estudantes, vindos das comunidades vizinhas, é feita uma divisão da turma com a professora Eunice, do Acuípe do Meio I, de 
modo que os estudantes pudessem frequentar a escola mais perto de sua comunidade. Além da turma organizada por Maristela, o professor Roquelino organiza uma turma com estudantes adultos, que funcionava no noturno. Maristela trabalha como professora voluntária até 2003, quando é contratada pelo Estado em Regime Especial de Direito Administrativo (REDA). É assim que Maristela relata o início da escola no Acuípe do Meio II.

Eu comecei a ensinar na minha comunidade como professora indígena em março de 2000. Não tinha sala. Tive que improvisar uma sala na casa de meu pai e ao mesmo tempo embaixo de uma árvore; quando estava fazendo sol, eu ensinava debaixo da árvore, pois tinha mais espaço para 52 alunos. Quando estava chovendo eu ensinava na casa de meu pai, mesmo o espaço sendo pequeno. As cadeiras eram esteiras colocadas no chão para os alunos sentarem. Comecei a ensinar a 52 alunos. (ESCOLA ESTADUAL INDÍGENA TUPINAMBÁ DE OLIVENÇA, 2013).

Em 2001, juntamente com a ajuda da comunidade e da CARE, que já atuava no Acuípe do Meio I, como já referido, é construída uma sala de aula que funciona até 2009. Em 2010, Maristela volta a lecionar na casa de seu pai. No ano seguinte, é construído o Núcleo que funciona atualmente, com a ajuda da comunidade, uma única sala, feita de taipa, com cobertura de eternit e com chão batido.

Em 2012, visitei este Núcleo, juntamente com José Carlos e Maria Jesuína, que naquele momento atuavam como pesquisadores do Observatório da Educação Escolar Indígena, vinculados ao Território Etnoeducacional Yby Yara, sob coordenação da professora América Cézar, da Universidade Federal da Bahia (UFBA). Na oportunidade, conversamos com o professor Roquelino, que nos apresentou as dificuldades enfrentadas por este Núcleo:

0 espaço pequeno atrapalha um pouco porque atender a uma série e atender outra é complicado; a gente leva porque a gente tem jeito mesmo, né? A gente sempre procura um jeitinho para a atender às crianças. As maiores dificuldades que a gente tem na escola é a falta de material; aqui a gente não tem ajuda nenhuma do Estado; aqui a gente fez mesmo na raça, nós mesmos, com a contribuição da comunidade; do Estado aqui mesmo só tem essas carteiras, e mesmo assim a gente está em falta porque tem aluno sentado em carteira que não tem braço, e esse armário. Essas telhas que cobrem o Núcleo fui eu, a professora Maristela e a professora Elenildes que compramos. 0 cimento, eu quem comprei, junto com o pessoal da comunidade, com os pais que se interessam, e estamos ajeitando aí. A gente depende de material porque trabalhar com criança sem material é problema. Os pais querem o melhoramento da escola. Os estudantes, agora mesmo, estão questionando a falta de merenda; o que mais eles se preocupam é com a falta de merenda, mas eles estão tranquilos. Para eles é uma alegria ter aula, e tendo merenda a alegria é maior ainda. Segundo dizem, a merenda não chegou ainda aqui porque os carros não estão rodando para as comunidades, porque, segundo Maristela, na escola sede já tem merenda. Para chegar aqui, só quando os carros estiverem rodando, para a gente ir à escola sede e pegar a merenda. (ROQUELINO, agosto de 2012).

A conversa que tivemos com Roquelino foi realizada no Núcleo escolar. Na ocasião, encontrava-se lá também seu Otacílio, liderança e morador da comunidade. Perguntamos como estes viam a escola indígena, se esta era ideal para seus filhos e o que eles queriam em termos de melhora para a escola. Nisso, Roquelino responde:

A parte de mudança, precisa de muita coisa ainda; já tem um começo, já bem adiantado, mas ainda falta melhorar ainda alguma coisa, como lá na escola sede mesmo; ela precisa ter esse espaço, com as ferramentas, com os materiais adequados, para que os professores responsáveis tenham esse acesso a esse material para poder estar ensinando às crianças. Isso ainda falta lá, porque no museu [referindo-se ao museu na escola em Sapucaeira], que está exposto, mas ainda falta isso aí. (ROQUELINO, agosto de 2012).

O senhor Otacílio acrescenta à fala de Roquelino:

Eu vejo que já melhorou bastante do que era, com aquele Colégio grande ali. Como a dona diretora fala, 'isso aqui é um espaço que tem que ser ocupado pelo índio, eu estou aqui ocu- 
pando uma vaga do índio'. Então, o índio tem que estudar para se formar para ser o diretor, o vice-diretor, tudo lá dá comunidade, porque aí ele já vai ensinar a cultura ao próprio índio, ao seu filho que estuda lá e ao filho do parente, incentivando que ele vá fazendo as coisas; tem que ter o dia também da professora estar com seus alunos todos na cultura, não é todo dia, mas que seja um dia na semana; a professora, que é a principal, que é a chefe que está educando as crianças, e ter o dia para os alunos irem com sua fardazinha, para ficar tudo organizado e já ir crescendo naquilo ali. Isso precisa ter, a professora já tem que ir ensinando às crianças também, ela está ali para ensinar a leitura, mas a cultura também, ela que é uma índia, que já está lá ocupando aquele espaço. Então isso precisa mudar muito. Têm muitos que têm que voltar para estudar o próprio índio, porque acontece o seguinte, eu ali vejo que tem muita mistura [referindo-se à presença de estudantes não indígenas na escola], tem parte que o índio já não vai ensinar, cada um tem sua cultura diferenciada, então precisa dessa organização, porque o que você vai ensinar ao índio, a um parente seu, você não vai ensinar ao outro, aí você vai ter que ter a parte dele. Por isso tem muitos na escola sede [referindo aos estudantes não indígenas] que às vezes não querem usar um cocar, uma tanga, porque ele é diferenciado, ele quer a diferença dele, não é isso? Então precisa mudar essas coisas na escola. É isso que eu tenho para explicar a vocês (OTACÍLIO, agosto de 2012).

Muitas das questões que atravessam a escola indígena, também expressas nas falas de Roquelino e Otacílio, estão bem situadas na tese de Santana (2015): uma escola indígena frequentada, também, por não indígenas e as tensões que emergem nesta relação, especialmente no que diz respeito ao que e como deve ser ensinado; uma escola que está para o aprendizado da leitura, da "letra", como disse dona Lourdes, anciã tupinambá, mas também da cultura; o papel que o professor desempenha nesse processo; como a cultura deve "aparecer" na escola, como deve ser ensinada; o entendimento (ou entendimentos) do que é a cultura, do que ela é capaz de produzir e agenciar, dentre tantas outras coisas.
Quando fizemos essa visita, lecionavam na comunidade as professoras Maristela e Elenildes, em turmas multisseriadas com estudantes da educação infantil ao ensino fundamental do primeiro ao segundo ano. Roquelino encontrava-se ensinando na escola sede, no noturno, para as turmas de Educação de Jovens e Adultos, como professor de cultura. Em 2014, lecionavam neste Núcleo as professoras Maristela Santos Silva (turma multisseriada) e Naiane Silva (educação infantil), para aproximadamente 20 alunos.

\section{Núcleo Abaeté/Santana}

A retomada desta área fora organizada pelo cacique Agebê logo após a reintegração de sua primeira retomada na Fazenda Cachoeira. Muitas das famílias indígenas que estavam nesta primeira área reintegrada anteriormente trabalhavam como "meeiros" nas fazendas locais, e por terem aderido ao movimento dos Tupinambá, não puderam mais retornar para seus trabalhos. Provavelmente, por ocasião de dissidências internas, esta retomada passou a ser gerida por uma antiga liderança deste cacique que, passado algum tempo, também acabou se tornando cacique. Posteriormente, este último acabou saindo de cena, deixando o lugar para a irmã, que passou a ser considerada a cacique local. Atualmente, a aldeia Abaeté permanece sob a coordenação desta última cacique (Indiara) e de seu companheiro, que é também o vice-cacique. A cacique e seu vice vivem em uma casa de alvenaria que já existia na propriedade, onde funcionava também o núcleo escolar (ROCHA, 2014).

Em 2009 foi criado o Núcleo de Abaeté pelas professoras Maria Lenice e Eliane Araújo, em uma área de retomada. Todavia, o movimento em torno da escola, nesta região, já vinha se constituindo desde 1999, com Maria Lenice e Helena, ambas vinculadas ao movimento indígena e apoiadas pelo CAPOREC-FASE, articulado por Núbia e Pedrísia. Com a saída de Helena, Pita, agente de saúde, atual marido 
da cacique Indiara, assume as atividades no Núcleo. Todos esses professores, até 2003, trabalhavam como voluntários. Em 2003, com a saída de Maria Lenice e Pita, assumem Pinho e Eliane, agora contratados via Regime Especial de Direito Administrativo (REDA). Nesse período, as aulas aconteciam no pátio da casa do Tio Piroca (ESCOLA ESTADUAL INDÍGENA TUPINAMBÁ DE OLIVENÇA, 2013).

Em 2005, Admilson (mais conhecido como Katu), irmão da cacique, torna-se professor neste Núcleo, mudando-se para Olivença neste mesmo ano, o que provoca a saída de muitos estudantes para a escola Municipal. Neste período, alguns alunos continuavam com "dupla matrícula", frequentando tanto a escola do município (não indígena) quanto a indígena.

José Carlos, em certa ocasião, revelou-me que no início do movimento (referindo-se ao Movimento dos Tupinambá em torno do seu reconhecimento étnico) algumas famílias colocavam os filhos em escolas do Município de Ilhéus em um turno e, no turno oposto, na escola indígena. Segundo ele, muitos pais viam na escola indígena um tipo de "reforço" ao aprendizado dos seus filhos. A construção da escola em Sapucaeira teria provocado maior confiança em muitas dessas famílias em relação à qualidade da educação da escola indígena. Não encontrei essa "duplicidade de matrícula" enquanto estive em campo. Encontrei algumas famílias que ainda preferem que seus filhos estudem nas escolas do município, uma vez que as péssimas condições nas estradas e as chuvas, em muitas situações, durante o ano letivo, impedem que a escola funcione. 0 "não ter aula" é considerado um grande prejuízo para a aprendizagem dos estudantes. Como disse certa vez Roquelino, "um dia de estudo que a criança perde, já faz falta para ela”, reiterando que em 2011, diante das chuvas e da precariedade do transporte, "a escola teria deixado muito a desejar", referindo-se ao Núcleo do Acuípe do Meio II, mas também à escola indígena como um todo. Chegou a afirmar que, em outros Núcleos, sobretudo os que estão mais próximos às escolas do Município, alguns pais tinham transferido seus filhos para essas escolas. No final do ano letivo de 2011, Cleusa demonstrava grande preocupação, posto que muitos pais estavam pedindo transferência de seus filhos para a escola do município, tendo como argumento o fato de que na escola indígena "tinha pouca escola" (pouca aula). De fato, as muitas chuvas, no decorrer de 2011, paralisaram o funcionamento da escola por semanas. Por vezes, o ônibus que partia de Olivença com os estudantes e professores em direção à Sapucaeira teve que retornar diante do perigo oferecido pela estrada.

Em 2006, ocorreu uma retomada em Cachoeira, não muito distante desta localidade, fazendo com que muitos estudantes e suas famílias fossem para essa retomada. Seis meses depois, ocorre reintegração de posse, o que leva os estudantes e suas famílias a retornarem para Santana. Com a retomada, a escola vai a Cachoeira; com a reintegração, volta a Santana, sempre acompanhando este movimento e as tensões que o atravessam. No ano seguinte, alguns alunos foram para o município, enquanto outros permaneceram estudando em uma casa de farinha comunitária. A partir de 2008, a escola sede começa a oferecer transporte escolar, deslocando os estudantes de Santana para a escola em Sapucaeira (ESCOLA ESTADUAL INDÍGENA TUPINAMBÁ DE OLIVENÇA, 2013).

0 atual Núcleo de Abaeté foi, portanto, construído em 2009 e atende a estudantes de áreas de retomada (ele mesmo está em área de retomada) próximas e de outras comunidades. Em 2012 este Núcleo possuía 26 alunos, com idade entre 03 e 15 anos, tendo como professoras Maria Lenice e Maria Vitória (no final de 2011, a professora Eliane é remanejada para outro Núcleo, assumindo o seu lugar a professora Maria Vitória). 0 Núcleo atende à educação infantil e aos primeiros anos do Ensino Fundamental, na forma multisseriada. Entre 2011 e 2012, as aulas aconteciam na casa (varanda, alpendre) onde moram a cacique Indiara e sua família. Fiz muitas visitas a essa 
área de retomada e acompanhei aulas, além de participar de reuniões com pais e professores, juntamente com Gicélia e Cleusa.

Neste Núcleo, em 2014, estavam matriculados aproximadamente 60 estudantes, nos turnos matutino e vespertino. Nele lecionavam as professoras Maria Cristina Ramos de Assis e Ionara Cruz (educação infantil); Maria Vitória Ramos de Assis (quinto ano); Maria Cristina Ramos de Assis (primeiro e segundo ano); Maria Vitoria Ramos (terceiro e quarto ano). Amauri Amaral (filho da cacique) atuava nos serviços gerais e Ivanilda da Silva Pereira como merendeira.

\section{Núcleo Serra do Serrote}

A Serra do Serrote e a Serra das Trempes formam uma cadeia montanhosa, prolongando-se à Serra do Padeiro. Historicamente as serras constituem um lugar de refúgio para onde algumas famílias indígenas foram quando fugiram da vila de Olivença no início do século XX. Os mais velhos relatam que foi também lá que o caboclo Marcelino buscou abrigo enquanto estava sendo perseguido pelas autoridades e policiais no final dos anos 1930. Como na Serra do Serrote, a Serra das Trempes concentra os solos mais ricos da terra indígena, correspondendo à linha de fronteira com a denominada região cacaueira do sul da Bahia. Assim, algumas famílias indígenas que habitam esta área desenvolveram o cultivo do cacau em complemento a outros produtos derivados da mandioca e da pesca no rio Santana, aqui mais turbulento e rochoso. Tal como na região anterior, principalmente os homens incrementam a renda familiar trabalhando como meeiros para os fazendeiros da região (ROCHA, 2014; VIEGAS, 2007, 2009).

A construção do Núcleo começa com uma visita feita no início de 2001 por Valdelice, junto com Josenice (Nicinha), Núbia, Edcarlos e outros parentes à Serra do Serrote, objetivando identificar famílias indígenas que moravam nesta localidade, além de apresentar para essas famílias o Movimento Indígena de Olivença, que vinha se articulando e reivindicando os direitos dos indígenas. Nesta mesma visita, como meio de fortalecer a comunidade, Núbia propõe a Gilmara Batista, que à época só tinha estudado até a $4^{\underline{a}}$ série, ${ }^{8}$ que formasse uma sala de aula para atender aos estudantes daquela comunidade que nunca tinham frequentado a escola, buscando, ademais, atrair os estudantes que frequentavam a escola do município.

Núbia, além de propor a Gilmara a construção de uma sala de aula para os estudantes indígenas, incentiva-a no retorno aos estudos. Esta não aceita o convite de imediato. Conversa com a comunidade, fala da proposta trazida por Núbia e por Valdelice de uma "sala de aula diferenciada" para os estudantes daquela localidade e nisso recebe o apoio de muitas famílias. Começa a realizar a matrícula dos estudantes sem ter, ainda, um local onde as aulas pudessem acontecer. Inicialmente, cogitou-se ensinar na casa de farinha, sem, contudo, dar segmento, uma vez que as aulas atrapalhariam as pessoas quando estivessem produzindo farinha. Diante disso, improvisa um local com seu marido Valdo, coberto com palha de dendê e plástico, dando início, ainda em 2001, a uma turma formada por 18 estudantes. Neste local permaneceu por três anos. As reclamações dos estudantes diante do espaço apertado, a não existência de 18 carteiras que pudessem acomodá-los, além das chuvas que molhavam a escola, fizeram com que Gilmara, em 2004, transferisse a turma para a sala apertada de sua própria casa. Em 2005, com recursos próprios, comprou tábua, eternit, ripas e cimento e, juntamente com Valdo e Juarez, morador da comunidade, construiu uma sala de aula, na qual leciona até hoje, ao lado de sua casa (ESCOLA ESTADUAL INDÍGENA TUPINAMBÁ DE OLIVENÇA, 2013).

Em 2011, juntamente com Gicélia e Cleusa, participei de uma reunião com os pais dessa co-

8 Gilmara forma-se na segunda turma do Magistério Indígena do Estado da Bahia, que teve início em 2006 e término em 2011. 
munidade. Neste encontro, uma das principais queixas trazidas por Gilmara e Valdo estava relacionada à dificuldade de se trabalhar a cultura na escola, uma vez que alguns pais, por terem se tornado evangélicos, estavam impedindo que os filhos realizassem o Poranci e a pintura corporal. Outra queixa, que se estende para os demais Núcleos, direcionava-se às dificuldades de se trabalhar em condições precárias, em uma sala muito apertada e abafada, dificultando, segundo a professora, o aprendizado dos estudantes. Outra dificuldade enfrentada pelo Núcleo estava relacionada à não existência de um banheiro e de uma cozinha onde a merenda pudesse ser feita.

Em 2014, por falta de alunos, este Núcleo deixa de fincionar e a professora Gilmara Batista é transferida para a escola em Sapucaeira.

\section{Núcleo Tucum}

A aldeia Tucum foi retomada em 8 de outubro de 2005 por um grupo de 22 indígenas que, segundo os moradores desta retomada, estavam cansados de trabalhar para um fazendeiro, denominado Miguel Farias, na retirada de piaçava, com pouco retorno para os indígenas.

Espacialmente, a aldeia pode ser descrita como composta por três núcleos residenciais que, não necessariamente, se configuram por relações de parentesco, mas sim por um conjunto de casas próximas, nas quais algumas famílias vão se aproximando mais ou menos das outras. 0 primeiro e maior destes núcleos abriga as famílias moradoras junto à entrada da área; o segundo define-se pelas casas dispostas ao longo do caminho que acessa o núcleo escolar, há uma distância de meia hora caminhando desde a entrada; e por fim, o terceiro e mais afastado em relação à entrada, porém próximo ao rio, abriga não mais do que oito moradias. É este último espaço que os habitantes consideram como a 'sede' da aldeia, já que foi ali que se acomodaram logo que fizeram a retomada. Quando a área da Tucum foi retomada, o cacique responsável na ocasião era Rose. Porém, cerca de dois anos depois, os moradores manifestaram-se descontentes com o mesmo e escolheram então outro cacique - Itagibá, que se mantém desde então. (ROCHA, 2014, p. 84, grifo do autor).
O Núcleo Tucum foi criado em 2007 para "fortalecer a retomada" e como forma de atender às crianças de muitas famílias que se dirigiram para este local. 0 primeiro professor deste Núcleo foi Ramon Itajibá, que é também o atual cacique desta retomada. Neste mesmo ano, Ramon organiza uma turma com trinta estudantes, formada por jovens e adultos, no noturno, e passa a lecionar em uma pequena casa existente no local à época da retomada, com muitas dificuldades, uma vez que não existia energia elétrica. Em 2008, iniciaram-se as aulas para as crianças, no matutino, sob responsabilidade da professora Luciana Maria Santos Conceição (Ramon é alocado para o setor administrativo) que, desde 2004, trabalhava como voluntária na Serra Negra, permanecendo como professora deste Núcleo até meados de 2009, quando Ramon retorna à função de professor. Em 2012, com a transferência de Ramon para a escola em Sapucaeira, assume a professora Joelma Santos Bathomarco (ESCOLA ESTADUAL INDÍGENA TUPINAMBÁ DE OLIVENÇA, 2013).

Esse Núcleo atendia às crianças de educação infantil e dos primeiros anos do ensino fundamental. ${ }^{9}$ Para atender a essa nova demanda, em 2008 a comunidade constrói um novo espaço, um Núcleo novo, para a realização das aulas.

Em 2011, segundo os pais, a escola tinha funcionado muito pouco e isso tinha prejudicado o "desenvolvimento das crianças". Alguns pais, diante da situação, transferiram seus filhos para o Núcleo em Olivença e outros colocaram em escolas do Município. 0 certo é que a comunidade expressava grande preocupação com os destinos da escola, mesmo compreendendo as demais funções que o professor tinha frente à comunidade, diante da posição que ocupava. Em conversas com as famílias desta comunidade, elas relataram:

A escola daqui precisa de mais professores; é muita criança para uma pessoa tomar conta sozinha. Tem a escola aqui dentro, tem mais

9 Muitos jovens e adultos desta aldeia estudam na Escola sede em Sapucaeira, posto que em 2008 a turma de EJA foi extinta. 
criança, quer dizer, tinha que ter a sala dividida, cada criança com sua idade, como existe na escola municipal. Cada idade no seu canto, para não virar aquele bolo e a professora não ficar sem saber o que fazer, se dá atenção para os pequenos, para os médios, para os mais avançados. É uma dificuldade que acaba embolando nesse meio termo e acaba os moradores daqui procurando recursos lá fora; ele vai procurar colocar seu filho em um meio onde sabe que vai ter resposta. A organização é melhor, pode-se aprender melhor. (RAIMUNDA, abril de 2012).

Não coloco ela aqui [referindo-se a sua filha] por causa dessas dificuldades aí, falta de professor; falta muita aula. As crianças falam das aulas que ficam faltando. Quando chega no final de ano querem que os meninos passem a pulso. (LUCIANA, abril de 2012).

Sem aula é sempre um prejuízo, porque quando a criança para de estudar, ao invés de ela prosseguir adiante, ela vai pra trás. Às vezes já aprendeu, mas quando vai estudar novamente já esqueceu porque teve uma parada. Eu tiro pelo meu filho, quando ele para de estudar é como se ele nunca tivesse ido à escola. (ELIVANICE, abril de 2012).

É assim que dona Lourdes, anciã desta comunidade, avalia a educação do Núcleo Tucum:

A escola daqui manca desde o tempo que nasceu; ela já nasceu aleijada. Um dia estuda, outro não estuda. Essa daí, Jaqueline [sua neta], passou pelo milagre de Jesus. Ela estudava aqui. Passou para lá [Sapucaeira], mas graças a Deus ela disse que não tem nada que empate a ela. Tem outro pequeno, irmãozinho dela, que ainda está aqui, mancando também. Esse cacique [referindo-se a Itajibá] vai para Brasília, Salvador, FUNAI; ele também não está bem de saúde, que eu sei. Então ele dá aula um dia, outro dia não pode, outro dia não vem, outro dia vai tirar exame. 0 melhoramento aqui que falta é uma professora, porque ele sozinho não pode fazer isso não. Não é irresponsabilidade dele não. (LOURDES, abril de 2012).

Em 2014, foram matriculados 21 estudantes neste Núcleo, em sala multisseriada, funcionando no matutino, tendo como professoras Elenildes Ferreira dos Santos e Patrícia Brás dos Santos, além de Geovana de Jesus Santos (merendeira) e Valdinete Barbosa (serviços gerais).

\section{Núcleo Itapoã/Retomada}

\section{Itapoã}

A aldeia Itapoã encontra-se na região de Águas de Olivença. Sua localização, junto à costa sul da vila de Olivença e com acesso facilitado pela rodovia BA-001, permite aos moradores um trânsito relativamente frequente - e para alguns, inclusive, diário - em direção à escola sede (Sapucaeira), à cidade de Ilhéus e também a Olivença. É considerada uma retomada (aldeia) de sucesso e abriga famílias que fazem parte do cacicado de Jamapoty. Da época da retomada até o presente momento, a conquista da permanência no lugar foi um grande passo que se sucedeu com a construção das casas, dos roçados (de mandioca, milho, feijão) e da casa de farinha. As casas são todas de taipa (estrutura de troncos de árvore e paredes de barro) e cobertas com telhas de amianto. Em comparação a outras aldeias, esta apresenta uma disposição espacial das casas que lhe é peculiar. Sob uma área plana, a maioria das moradias está disposta em duas fileiras que se alinham de frente uma para a outra, formando ao centro um caminho amplo que permite inclusive o acesso de carros. No meio do caminho se localiza uma cabana, onde acontecem as reuniões entre os moradores, a cacique e demais lideranças (ROCHA, 2014).

O núcleo escolar desta retomada (aldeia) primeiramente se encontrava junto à "cabana", no aglomerado principal das casas. Contudo, como a estrutura de taipa acabou se deteriorando, em 2011, a comunidade constrói outra escola, na entrada da aldeia, com duas salas de aula, que atendem crianças da educação infantil e do Ensino Fundamental I. Nas visitas que fiz a essa aldeia, pude perceber que era um dos núcleos com maior quantidade de estudantes, o que deixava as salas de aula muito apertadas e com pouca movimentação para as crianças, especialmente as de educação infantil, que pareciam muito desconfortáveis nas carteiras que, por serem muito altas, deixavam-nas com as pernas penduradas e impossibilitadas de se 
movimentarem com facilidade. As professoras, para driblarem essas dificuldades, realizavam aulas sob árvores, circulavam com as crianças pela comunidade, faziam trilhas, levavamnas para tomar banho nos córregos, além de estender o tempo do intervalo, sempre muito aguardado pelas crianças, momento em que estas realizavam diferentes brincadeiras, como jogar bola, subir em árvores, faze gangorra etc.

É considerado um dos Núcleos com maior autonomia em relação à escola sede, especialmente porque a cacique desta comunidade sempre fez oposição ${ }^{10}$ à direção da escola. É certo, porém, que as relações, atualmente, são mais tranquilas, quando comparadas ao início da gestão de Cleusa, sobretudo porque esta construiu novas redes de alianças que envolvem a escola e demais cacicados (especialmente os Núcleos que estão mais diretamente sob a influência de um(a) cacique). A partir dessas novas relações, não foi muito incomum ouvir, por parte desses aliados, que a escola "ficou melhor". Melhor tanto no sentido da qualidade quanto no que se refere ao abrandamento das disputas em torno da escola, envolvendo diferentes cacicados.

De professores desta aldeia e da própria cacique ouvi reclamações de que famílias evangélicas que ali residem têm trazido dificuldades para a "vivência da cultura na comunidade e na escola", posto que muitas delas não querem participar do Poranci, desvalorizam a cultura ou impedem que seus filhos se pintem na escola. Esta mesma dificuldade ouvi em outras comunidades, como na Serra do Serrote, quando a professora Gilmara, em reunião com a direção da escola, expõe esta situação que, segundo ela, "tem enfraquecido a cultura na comunidade", como já referido.

Nos primeiros meses da pesquisa, por construir relações com pessoas que faziam parte

10 Quando Cleusa assume a direção da Escola Indígena Tupinambá de Olivença, lá colocada pelo Estado, as disputas em torno da escola eram mais intensas, especialmente porque, naquele momento, a direção da escola era comandada, como ouvi algumas vezes, por um grupo de professores que pertenciam ao cacicado de Jamapoty. de outros cacicados, alguns considerados oposição à cacique, fui olhado com certa desconfiança por parte de alguns professores que lecionavam em Sapucaeira e que pertenciam ao cacicado de Jamapoty. Esta desconfiança pude perceber na fala de alguns professores em relação ao ensino da língua Tupinambá que vinha sendo realizado por uma linguista, professora da Universidade Estadual do Sudoeste da Bahia (UESB), Consuelo Paiva, que tinha sido levada aos Tupinambá por uma grupo de professores que, ao menos naquele contexto, não faziam parte do cacicado de Jamapoty. Em conversa com uma destas professoras que já lecionava Tupi na escola, irmã da cacique, esta questiona, inclusive, a competência da linguista, afirmando que "há um bom tempo já vinha ensinando tupi na escola". Esta professora, inclusive, não participava das aulas de Tupinambá que a linguista vinha realizando em Olivença.

0 certo é que este Núcleo tem caminhado com maior autonomia em relação à escola sede, o que, provavelmente (e parece ser esse o desejo da cacique Jamapoty e de seus professores), em futuro não muito distante, produzirá uma outra escola, como ouvi da própria direção e de professores, como ocorreu com o Núcleo de Acuípe de Baixo. Em 2014, funcionavam neste Núcleo, além das turmas de Educação Infantil e os primeiros anos do Ensino Fundamental (primeiro ao quinto), turma de Educação de Jovens e Adultos (Eixos um, dois e três), atendendo a mais de 90 estudantes, distribuídos entre os três turnos, tendo como professores: Daniela Ferreira dos Santos e Juvani do Amaral (educação infantil); Marcelo Sá e Luciana Rodrigues (educação infantil); Adriana Almeida (primeiro e segundo anos); Maria Luiza Carvalho Nascimento (quarto e quinto anos); Maria Gorete Amaral (EJA - Eixo 1); Elen França (EJA - Eixos 2 e 3); Valéria Correia (quinto e sexto anos); Maria das Graças (quinto e sexto anos); além das merendeiras Lucília Batista Costa e Sueli Silva Santos; e Leandro Amaral Santos e José Carlos Silva Santos (serviços gerais). 


\section{Por que os Tupinambá fazem escola?}

Os Tupinambá fazem escola para resistir e resistem fazendo escola. Estudar é resistir. Possibilidade, inclusive, para se manter no território, cuidando dos parentes. Se a escola produz novos postos de trabalho e, portanto, novas funções, novos empregos, que são, também, disputados internamente, a partir do modo como se faz política, que envolve a relação entre caciques, escola e professores, é verdade, também, que muitos permanecem no território, "fortalecendo a cultura, a luta, o movimento", porque tem a escola e as vantagens que esta oferece, a exemplo de emprego. Como já foi dito, a situação econômica de muitas famílias é dificílima. Para algumas delas, a possibilidade de renda vem da escola, do emprego que esta oferece. Outras, sem muita sorte, veem-se obrigadas a procurar emprego muito distante, a exemplo de São Paulo, em cidades próximas e na própria Ilhéus. Da mesma forma, famílias que vivem fora de Olivença, em outras cidades, ou mesmo em bairros de Ilhéus, são atraídas, "retomadas" para a luta junto ao movimento indígena.

Estudar é como "fazer retomada", em duplo sentido: é resistência, diante dos perigos, das dificuldades que se enfrenta para chegar à escola. Alguns desses perigos são muito reais, sobretudo quando se instauram tensões mais agudas com os fazendeiros, dentro do próprio território. Ir à escola, nessas circunstâncias, é sempre perigoso. Ouvi de professores que, nestas situações, as crianças, especialmente as que precisam atravessar fazendas para chegar à escola, têm que esconder "sua cultura", a pintura corporal, colares, tanga, como forma de não serem facilmente identificadas e, com isso, sofrerem ataques. Outras, ainda, segundo relato de um professor, "não querem chegar pintadas em casa porque têm medo do patrão, de serem expulsas da terra. Medo de sair da terra e não ter para onde ir".

Por outro lado, estudar é "retomar", de forma sempre atualizada, através do que se aprende na e pela escola, a história dos antepassados, suas lutas, resistências; é produzir e "estar na cultura", como temos afirmado. Certa vez, um professor, que também estudava na escola indígena, me relatou:

Fui crescendo no movimento indígena, fui adquirindo a cultura, fui crescendo na cultura, fui me tornando mais índio, fui ouvindo os mais velhos falarem. Com 14 anos comecei a me questionar: será que os não indígenas estão me percebendo como índio? 0 que estão achando de mim? Quando eu entro na escola indígena começo a me fortalecer novamente porque na escola se falava muito sobre a cultura, sobre nossa história [quando foi realizada esta entrevista, em minha casa em Olivença, o professor encontrava-se cursando o ensino médio, na modalidade EJA, na escola indígena]. (ALINOEL, outubro de 2011).

Em uma situação em que os conflitos se acentuaram, na vila de Olivença, nas aldeias e retomadas, na Serra do Padeiro, fruto da disputa em torno da demarcação do território, foi realizada reunião, em Sapucaeira, com pais, lideranças, caciques e professores para que se decidisse pela continuidade ou paralisação das aulas. Os pais presentes, praticamente todos, decidiram pela continuidade. Muitos professores que lecionavam nos Núcleos entregaram documentos assinados pelos pais à diretora Cleusa, em que estes decidiam pela continuidade. 0 senhor Joselito, liderança da comunidade Serra Negra, chegou a dizer que se as aulas não continuassem, os pais desta comunidade iriam tirar os filhos da escola. Os caciques presentes, quase todos, pretendiam o cancelamento das aulas, uma vez que, segundo eles, a situação era de muito perigo, o que colocaria em risco a vida de muita gente. Um cacique, que morava em área de retomada, mesmo considerando a educação prioridade, afirmou que a ocasião era propícia para usar o "diferenciado de forma inteligente" (neste caso, o diferenciado da legislação, que garante calendário específico, além de outras estratégias pedagógicas que não se limitam à sala de aula) para compensar "as aulas perdidas". Outro cacique sugere, já que se aproximava do dia da Caminhada, que a escola pudesse montar 
grupos de trabalho voltados para a organização desta, nas próprias comunidades, como forma de "compensar estas aulas perdidas".

Para Renildo, cacique da retomada do Mamão, "o resgate da aldeia vai se dando com a construção da escola". Essa fala é central e aponta os diferentes caminhos que explicam o movimento que expande a escola por todo o território, movimento este que experimenta tensões, conflitos, rupturas, já que envolve disputas em torno desta. As escolas, portanto, atuam em defesa do território, já que atraem e fixam famílias nestas áreas, que investirão na produção de uma nova aldeia e de novos "lugares", neste movimento em que se "retoma" parentes, território, ao mesmo em que se atua em defesa destes. A "luta" que os Tupinambá empreendem em defesa do território é a mesma que se volta para produzir e manter suas escolas. Nesse sentido, como sugeriu Susana Viegas, no momento da arguição da tese de Santana (2015), "lutar envolve princípios éticos e esforço sobre o mundo" e, do mesmo modo, "lutar está relacionado à ideia de Tupinambá forte na cultura. Estar na cultura passa por experimentar a cultura, através das ligações intersubjetivas".

Outro aspecto não menos importante é que a escola tem produzido um tipo de enfrentamento mais direto com o Estado, legitimando lutas e produzindo novas demandas. Construir escolas tem sido, inclusive, uma forma de negociar com o Estado, posto que é muito comum ouvir, quando os Tupinambá reclamam a construção de novas Núcleos, a seguinte posição por parte dos que representam o Estado, a exemplo da Secretaria de Educação: "não podemos construir escolas em áreas de retomada, já que o território não foi ainda homologado." No entanto, os Tupinambá continuam construindo e expandindo suas escolas, produzindo novas alianças e fortalecendo o movimento indígena. Antes que o Estado reconhecesse a Escola dos Tupinambá, estes já se empenhavam em sua construção, inclusive como meio de atuar frente ao Estado. Não é à toa quando dizem que "tudo começou com a escola".

\section{REFERÊNCIAS}

ALARCON, D. F. 0 retorno da terra: as retomadas na aldeia Tupinambá da Serra do Padeiro, sul da Bahia. 2013. 343f. Dissertação (Mestrado em Estudos Comparados sobre a América) - Instituto de Ciências Sociais, Programa de Pós-Graduação em Estudos Comparados Sobre as Américas, Universidade de Brasília (UnB), Brasília, DF, 2013.

CARNEIRO DA CUNHA, M. Políticas culturais e povos indígenas: uma introdução. In: CARNEIRO DA CUNHA, M.; CESARINO, P. de N. (org.). Políticas culturais e povos indígenas. São Paulo: Cultura Acadêmica, 2014. p. 9-21.

COHN, C.; SANTANA, J. V. J. de. A antropologia e as experiências escolares indígenas. Revista Pós Ciências Sociais, São Luís, v. 13, n. 25, p. 61-86, 2016.

COLLET, C. L. G. Ritos de civilização e cultura: a escola bakairi. 2006. 391f. Tese (Doutorado em Antropologia Social) - Programa de PósGraduação em Antropologia Social, Museu Nacional, Universidade Federal do Rio de Janeiro (UFRJ), Rio de Janeiro, 2006.

COSTA, E. F. de J. Da corrida de tora ao poranci: a permanência histórica dos Tupinambá de Olivença no Sul da Bahia. 2013. 203f. Dissertação (Mestrado em Desenvolvimento Sustentável) - Universidade de Brasília (UnB), Brasília, DF, 2013.

ESCOLA ESTADUAL INDÍGENA TUPINAMBÁ DE OLIVENÇA. Projeto Político Pedagógico (PPP). Olivença, BA, 2013.

FERREIRA, S. M. M. “A luta de um povo a partir da educação": Escola Estadual Indígena Tupinambá da Serra do Padeiro. 2011. Dissertação (Mestrado em E ducação) - Programa de Pós-Graduação em Educação, Universidade do Estado da Bahia (UNEB), Salvador, 2011.

FERREIRA, S. M. M. Escola Indígena Tupinambá da Serra do Padeiro. In: CÉSAR, A. L. S.; COSTA, S. L. (org.). Pesquisa e escola: experiências em educação indígena na Bahia. Salvador: Quarteto, 2013. p. 285-305.

LOPES DA SILVA, A. Educação para a tolerância e povos indígenas no Brasil. In: GRUPIONI, L. D. B.; VIDAL, L.; FISCHMANN, R. (org.) Povos indígenas e tolerância: construindo práticas de respeito e solidariedade. São Paulo: EDUSP, 2001. p. 99-131.

MAGALHÃES, A. M. A luta pela terra como "oração": sociogênese, trajetórias e narrativas do 
“movimento” Tupinambá. 2010. 151f. Dissertação (Mestrado em Antropologia Social) - Universidade Federal do Rio de Janeiro (UFRJ), Rio de Janeiro, 2010.

MAGALHÃES, J. C. B. "O que nós queremos é uma escola com o cheiro do nativo": os modos de apropriação da escola pelos Tupinambá de Olivença. 2019. 112f. Dissertação (Mestrado em Antropologia Social) - Programa de Pós-Graduação em Antropologia Social, Universidade de Brasília (UnB), Brasília, DF, 2019.

MAINARDI, C. Construindo proximidades e distanciamentos: etnografia Tupi Guarani da Terra Indígena Piaçaguera/SP. 98f. Dissertação (Mestrado em Antropologia Social) - Universidade Federal de São Carlos (UFSCar), São Carlos, SP, 2010a.

MAINARDI, C. O papel da escola no resgate cultural dos Tupi Guarani da Terra Indígena Piaçaguera-SP. Revista Pós em Ciências Sociais, v. 7, n. 14, p. 4557, jul./dez. 2010b. Disponível em: http://www. periodicoseletronicos.ufma.br/index.php/rpcsoc/ article/view/562. Acesso em: 08 jun. 2013.

MARCIS, T. A “hecatombe de Olivença”: construção e reconstrução da identidade étnica - 1904. 2004. 163f. Dissertação (Mestrado de História) Programa de Pós-Graduação em História Social, Universidade Federal da Bahia (UFBA), Salvador, 2004.

MEJÍA LARA, A. E. "Estar na cultura”: os Tupinambá de Olivença e o desafio de uma definição de indianidade no Sul da Bahia. 2012.153f. Dissertação (Mestrado em Antropologia Social) - Programa de Pós-Graduação em Antropologia Social, Universidade Estadual de Campinas (UNICAMP), Campinas, SP, 2012.

MESSEDER, M. L. L. A construção da licenciatura indígena da UNEB: os dilemas, os desafios, os limites e as possibilidades. In: CÉSAR, A. L. S.; COSTA, S. L. (org.). Pesquisa e escola: experiências em educação indígena na Bahia. Salvador: Quarteto, 2013. p. 37-54.

MESSEDER, M. L. L.; FERREIRA, S. M. M. Educação escolar entre os Tupinambá da Serra do Padeiro: reflexões sobre a prática docente e o projeto comunitário. Revista da FAEEBA, v. 19, n. 33, p. 185-198, jan./jun. 2010.

PEIRANO, M. A favor da etnografia. Rio de Janeiro: Relume Dumará, 1995.
ROCHA, C. C. da. "Bora vê quem pode mais": uma etnografia sobre o fazer política entre os Tupinambá de Olivença (Ilhéus, Bahia). 2014. 303f. Tese (Doutorado em Antropologia Social) - Programa de Pós-Graduação em Antropologia Social, Universidade Federal de Santa Catarina (UFSC), Florianópolis, 2014.

SAHLINS, M. Cultura na prática. Rio de Janeiro: UFRJ, 2004.

SANTANA, J. V. J. de. “A letra é a mesma, mas a cultura é diferente": a escola dos Tupinambá de Olivença. 2015. 241f. Tese (Doutorado em Antropologia Social) - Programa de Pós-Graduação em Antropologia Social, Universidade Federal de São Carlos (UFSCar), São Carlos, SP, 2015.

SANTOS, M. V. A. Práxis pedagógicas e saberes culturais: diálogos com as professoras Tupinambá de Olivença/BA. 2016. 137f. Dissertação (Mestrado em Educação Profissional) - Programa de Pós-Graduação em Formação de Professores da Educação Básica, Universidade Estadual de Santa Cruz (UESC), Ilhéus, BA, 2016.

SILVA, N. B. da. Educação de jovens e adultos e a afirmação da identidade étnica do povo Tupinambá de Olivença - 1996 a 2004. 2006. Monografia (Especialização em Educação de Jovens e Adultos) - Universidade Estadual de Santa Cruz (UESC), Ilhéus, BA, 2006.

VIEGAS, S. de M. Socialidades Tupi: Identidade e experiência entre os índios-caboclos (Bahia/Brasil). 2003. 423f. Tese (Doutorado em Antropologia) Faculdade de Ciências e Tecnologia, Universidade de Coimbra, Coimbra, Portugal, 2003.

VIEGAS, S. de M. Terra calada: os Tupinambá na mata atlântica do sul da Bahia. Rio de Janeiro: 7 Letras, 2007.

VIEGAS, S. de M. Resumo do Relatório Circunstanciado de Delimitação da Terra Indígena Tupinambá de Olivença. Diário Oficial da União: seção 1, Brasília, DF, ano 146, n. 74, p. 52-57, 20 abr. 2009.

WEBER, I. Um copo de cultura: os huni kuin (Kaxinawá) do rio humaitá e a escola. Rio Branco: EDUFAC, 2006. 